Pacific Journal of Mathematics

AN ANALOGUE OF KOLMOGOROV'S INEQUALITY FOR A
CLASS OF ADDITIVE ARITHMETIC FUNCTIONS 


\title{
AN ANALOGUE OF KOLMOGOROV'S INEQUALITY FOR A CLASS OF ADDITIVE ARITHMETIC FUNCTIONS
}

\author{
JOSEPH E. COLLISON
}

Let $f$ be a complex valued additive number theoretic function (i.e., $f(m n)=f(m)+f(n)$ if $m$ and $n$ are relatively prime). This paper shows that $\sum D^{2}\left(p^{\alpha}\right) p^{-\alpha}=O\left(D^{2}(n)\right)$ or $\sum\left|f\left(p^{\alpha}\right)\right| p^{-\alpha}=O(D(n))$ (where the summations are over those $p^{\alpha} \leqq n, p^{\alpha}$ being a prime raised to a power) is sufficient to guarantee that the following analogue of Kolmogorov's inequality holds:

$$
\nu_{n}\left\{\operatorname{Max}_{k \leqq n}\left|f_{k}(m)-A(k)\right|>t D(n)\right\}=O\left(t^{-2}\right)
$$

where, if $p^{\alpha}|| m$ denotes the fact that $p^{\alpha}$ divides $m$ but $p^{\alpha+1}$ does not (i.e., $p^{\alpha}$ exactly divides $m$ ), then

$$
\begin{gathered}
A(n)=\sum_{p^{\alpha} \leqq n} f\left(p^{\alpha}\right) p^{-\alpha}, \\
D^{2}(n)=\sum_{p^{\alpha} \leqq n}\left|f\left(p^{\alpha}\right)\right|^{2} p^{-\alpha}, \\
f_{k}(m)=\sum_{\substack{p^{\alpha} \leqq k \\
p^{\alpha} \| m}} f\left(p^{\alpha}\right),
\end{gathered}
$$

and

$$
\nu_{n}(\mathscr{S})=n^{-1} \sum_{\substack{m \leq n \\ m \in \mathscr{S}}} 1
$$

for any set $\mathscr{S}$.

It is known that

$$
\sum_{m \leqq n}|f(m)-A(n)|^{2} \leqq c_{0} n D^{2}(n)
$$

holds for all additive functions for some absolute constant $c_{0}$. This implies the analogue of Chebyshev's inequality. Hence it is of interest to determine whether the analogue of Kolmogorov's inequality also holds for all such functions. The author could not do this for all additive functions, but did find various sufficient conditions to guarantee the result. The two which were most general and verifiable for specific functions are stated in the opening paragraph.

The author proved his result in two stages. First he determined in Theorem 1 necessary and sufficient conditions for

$$
\sum_{m \leqq n} \operatorname{Max}_{k \leqq n}\left|f_{k}(m)-A(k)\right|^{2} \leqq c n D^{2}(n)
$$

to hold (which implies the analogue of Kolmogorov's inequality). 
The more manageable problem that resulted provided the basis for proving the result stated in the opening paragraph as well as an approach that might eventually help lead to the full solution of the problem.

1. Preliminaries. Let $p^{\alpha}$ and $q^{\beta}$ represent primes raised to a power. Given an integer $m$, let $L(m)$ be the largest $p^{\alpha}$ such that $p^{\alpha} \| m$ and let $S(m)$ be the smallest such $p^{\alpha}$. If $q^{\beta} \| m$ with $q^{\beta}>S(m)$, we shall denote by $\boldsymbol{r}^{\gamma}\left(m, q^{\beta}\right)$ the largest exact prime-power divisor of $m$ which is less than $q^{\beta}$.

The following well known facts are freely used in this article:

$$
\sum_{p \alpha \leq n} p^{-\alpha} \log p^{\alpha}=O(\log n)
$$

and

$$
\sum_{p^{\alpha} \leqq n} p^{-\alpha}=\log \log n+B+O\left(\log ^{-1} n\right)
$$

where $B$ is an absolute constant. The next lemma represents an extension of a known result of sieve methods.

Lemma. Given $1.9 \leqq b \leqq c \leqq n$, let $\mathscr{S}=\mathscr{S}(n, c, b)$ be the set of those $m, m \leqq n$, such that $p^{\alpha} \| m$ implies either $p^{\alpha} \leqq b$ or $p^{\alpha} \geqq c$. Then there exists an absolute constant $c_{1}$ such that

$$
\sum_{m \in \mathscr{S}} 1 \leqq c_{1} n(\log b) \log ^{-1} c \text {. }
$$

Proof. If for any $z \geqq 2$ we let

$$
\mathscr{C}=\{p: p<z \text { and } p \leqq b \text { or } p \geqq c\}
$$

and $\mathscr{S}^{\prime}=\{m: m \leqq n$ and $p \nmid m$ if $b<p<\min (c, z)\}$, then it is known $[1, \mathrm{p} .104]$ that

$$
\sum_{m \in \mathscr{S}^{\prime}} 1 \leqq z^{2}+n \log ^{-1} z \prod_{p \in \mathscr{C}}\left(1-p^{-1}\right)^{-1} .
$$

Since

$$
\left|\prod_{p \leqq x}\left(1-p^{-1}\right)-e^{-\gamma} \log ^{-1} x\right|<e^{-\gamma} \log ^{-3} x
$$

for $x>1$ where $\gamma$ is Euler's constant [3, p. 70], it follows that if we choose $z=n^{1 / 2} \log ^{-1 / 2} n$ and assume $3 \leqq b \leqq c \leqq z$, then

$$
\sum_{m \in \mathscr{J}^{\prime}} 1 \leqq \frac{n}{\log n}+\frac{e^{\gamma}\left(1+\log ^{-2} 3\right)}{(2 / 3)\left(1-\log ^{-2} 3\right)^{2}} \frac{n \log b}{\log c} \leqq 168 n(\log b) \log ^{-1} c .
$$

For the cases where $1.9 \leqq b<3$ or $z<c \leqq n$ or $z \leqq b \leqq c \leqq n$, note that it follows from the last result that 


$$
\sum_{m \in \mathscr{S}} 1 \leqq \frac{168 n(\log b)(\log 3)(\log n)}{(\log 1.9)(\log z)(\log c)} \leqq 910 \frac{n \log b}{\log c} .
$$

Now if we let $\mathscr{S}^{\prime \prime}$ be the set of $m, m \leqq n$, such that there exists a $p^{\alpha} \| m$ for which $b<p<c$ and $p^{\alpha} \geqq c$, then

$$
\sum_{m \in \mathscr{S}} 1 \leqq \sum_{m \in \mathscr{S},} 1+\sum_{m \in \mathscr{S} \prime \prime} 1 \text {. }
$$

Since

$$
\begin{aligned}
\sum_{m \in \mathscr{S}^{\prime \prime}} 1 & \leqq \sum_{b<p<c} \sum_{\log c / \log } \sum_{p \leqq \alpha \leqq \log n / \log p} \sum_{\substack{m \leq n \\
p^{\infty}|| m}} 1 \\
& \leqq n \sum_{b<p<c} \sum_{\alpha \geqq \log c / \log p} p^{-\alpha} \\
& \leqq 2 n c^{-1} \sum_{p<c} 1 \leqq \frac{2 n}{c}\left(\frac{1.26 c}{\log c}\right) \frac{\log b}{\log 1.9} \\
& \leqq 4 n(\log b) \log ^{-1} c
\end{aligned}
$$

we see that choosing $c_{1}=914$ yields (1.1). This completes the proof.

2. General necessary and sufficient conditions. The next theorem is of theoretical significance. However, since it is not easy to apply the results to specific functions it is not very practical.

THEOREM 1. Given an additive complex valued arithmetic function $f$, necessary and sufficient conditions for

$$
\sum_{m \leqq n} \operatorname{Max}_{k \leqq n}\left|f_{k}(m)-A(k)\right|^{2} \leqq c_{2} n D^{2}(n)
$$

to hold for some constant $c_{2}$ are:

$$
\sum_{m \leqq n} \operatorname{Max}_{q^{\beta} \| m}\left|f_{q^{\beta}}(m)-A\left(q^{\beta}\right)\right|^{2} \leqq c_{3} n D^{2}(n)
$$

and

$$
\sum_{m \leqq n} \operatorname{Max}_{\substack{\alpha^{\beta} \| m \\ S(m)<q^{\beta}<L(m)}} \operatorname{Max}_{\boldsymbol{r}\left(m, q^{\beta}\right) \leqq k<q^{\beta}}\left|A(k)-A\left(\boldsymbol{r}^{\gamma}\right)\right|^{2} \leqq c_{3} n D^{2}(n)
$$

for some constant $c_{3}$. Similarly, necessary and sufficient conditions for

$$
\nu_{n}\left\{\underset{k \leqq n}{\operatorname{Max}}\left|f_{k}(m)-A(k)\right|>t D(n)\right\} \leqq c_{2} t^{-2},
$$

the analogue of Kolmogorov's inequality, to hold for all real $t>0$ and for some constant $c_{2}$ are:

$$
\nu_{n}\left\{\underset{q^{\beta} \| \mid m}{\operatorname{Max}}\left|f_{q^{\beta}}(m)-A\left(q^{\beta}\right)\right|>t D(n)\right\} \leqq c_{3} t^{-2}
$$

and 


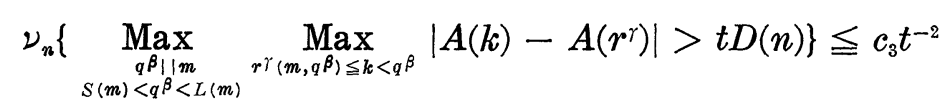

for some constant $c_{3}$. Note that (2.2) and (2.3) imply (2.5) and (2.6). Also, $c_{2}$ depends only on $c_{3}$ (which may depend on $f$ ).

$$
\begin{gathered}
\text { Proof. Let } T=T(n, m)=\operatorname{Max}_{k \leqq n}\left|f_{k}(m)-A(k)\right| . \text { Then } \\
T \leqq \operatorname{Max}\left(T_{1}, T_{2}, T_{3}\right)+T_{4}+T_{5}
\end{gathered}
$$

where

$$
\begin{aligned}
& T_{1}=\operatorname{Max}_{k<S(m)}|A(k)| \\
& T_{2}=\operatorname{Max}_{L(m)<k \leqq n}|A(k)-A(L(m))| \\
& T_{3}=\operatorname{Max}_{r^{\gamma}(m, L(m))<k \leqq L(m)}\left|A(k)-A\left(\boldsymbol{r}^{\gamma}\right)\right| \\
& T_{4}=\operatorname{Max}_{q^{\beta}|| m}\left|f_{q^{\beta}}(m)-A\left(q^{\beta}\right)\right|
\end{aligned}
$$

and

$$
T_{5}=\operatorname{Max}_{\substack{q^{\beta}|| m \\ S(m)<q^{\beta}<L(m)}} \operatorname{Max}_{r \gamma\left(m, q^{\beta}\right) \leq k<q^{\beta}}\left|A(k)-A\left(r^{r}\right)\right| .
$$

Using Schwarz's inequality and the lemma we see that

$$
\begin{aligned}
\sum_{m \leqq n} T_{1}^{2} & \leqq \sum_{m \leqq n} D^{2}(S(m)) \sum_{p^{\alpha}<S(m)} p^{-\alpha} \\
& \leqq D^{2}(n) \sum_{p \alpha \leqq n} p^{-\alpha} \sum_{m \in \mathscr{S}\left(n, p^{\alpha}, 1,9\right)} 1 \\
& \leqq c_{1} n D^{2}(n)(\log 1.9) \sum_{p^{\alpha} \leqq n} p^{-\alpha} \log ^{-1} p^{\alpha} \\
& =O\left(n D^{2}(n)\right)
\end{aligned}
$$

and

$$
\begin{aligned}
\sum_{m \leqq n} T_{2}^{2} & \leqq D^{2}(n) \sum_{m \leqq n} \sum_{L(m)<p^{\alpha} \leqq n} p^{-\alpha} \\
& \leqq D^{2}(n) \sum_{p^{\alpha} \leqq n} p^{-\alpha} \sum_{m \in \mathscr{S}} \sum_{\left(n, n, p^{\alpha}\right)} 1 \\
& \leqq c_{1} n D^{2}(n)(\log n)^{-1} \sum_{p^{\alpha} \leqq n} p^{-\alpha} \log :^{\alpha} \\
& =O\left(n D^{2}(n)\right) .
\end{aligned}
$$

Also,

$$
\begin{aligned}
\sum_{m \leqq n} T_{3}^{2} & \leqq D^{2}(n) \sum_{m \leqq n} \sum_{\operatorname{rr}(m, L(m))<p^{\alpha}<L(m)} p^{-\alpha} \\
& \leqq D^{2}(n)\left(S_{1}+S_{2}+S_{3}\right)
\end{aligned}
$$

where

$$
S_{1}=\sum_{n^{1 / 2} \leqq p^{\alpha}<n} p^{-\alpha} \sum_{m \leqq n} 1=O(n)
$$

and where (noting that there are no exact divisors of $m$ larger than $p^{\alpha}$ once $m$ is divided by $L(m)$ in the sum) 


$$
\begin{aligned}
S_{2} & =\sum_{p^{\alpha}<n^{1 / 2}} p^{-\alpha} \sum_{p^{\alpha}<q^{\beta} \leqq n p^{-\alpha}} \sum_{\left.m \in S_{(n q}-\beta, n q-\beta, p^{\alpha}\right)} 1 \\
& \leqq c_{1} n \sum_{q^{\beta} \leqq n}\left(q^{\beta} \log n q^{-\beta}\right)^{-1} \sum_{p^{\alpha} \leqq M \min \left(q^{\beta}, n q^{-\beta}\right)} p^{-\alpha} \log p^{\alpha} \\
& =O(n)+O\left(n \sum_{q^{\beta}<n^{1 / 2}}\left(\log q^{\beta}\right)\left(q^{\beta} \log n q^{-\beta}\right)^{-1}\right) \\
& =O(n)+O\left[n \log ^{-1} n \sum_{q^{\beta}<n^{1 / 2}} q^{-\beta} \log q^{\beta}\right] \\
& =O(n)
\end{aligned}
$$

and

$$
\begin{aligned}
S_{3} & =\sum_{p^{\alpha}<n^{12}} p^{-\alpha} \sum_{n p^{-\alpha<q} \beta_{\leqq n}} n q^{-\beta} \\
& =O(n)+O\left[n \sum_{p^{\alpha}<n^{1,2}} p^{-\alpha} \log \frac{\log n}{\log n p^{-\alpha}}\right] \\
& =O(n)+O\left[n \sum_{p^{\alpha}<n^{1 / 2}} p^{-\alpha} \log \left[1-\frac{\log p^{\alpha}}{\log n}\right]^{-1}\right] \\
& =O(n)+O\left[n \log ^{-1} n \sum_{p^{\alpha}<n^{1 / 2}} p^{-\alpha} \log p^{\alpha}\right] \\
& =O(n) .
\end{aligned}
$$

Hence

$$
\sum_{m \leqq n} \operatorname{Max}\left(T_{1}^{2}, T_{2}^{2}, T_{3}^{2}\right) \leqq c_{4} n D^{2}(n)
$$

where $c_{4}$ is absolute and does not depend on $f$. From this it also follows that

$$
\nu_{n}\left\{\operatorname{Max}\left(T_{1}, T_{2}, T_{3}\right)>t D(n)\right\} \leqq c_{4} t^{-2}
$$

for all real $t>0$. This establishes the sufficiency of the conditions.

The fact that $T \geqq T_{4}$ establishes the necessity of (2.2) and (2.5). The necessity of (2.2) and (2.5) together with $T \geqq T_{5}-T_{4}$ establishes the necessity of (2.3) and (2.6). This completes the proof.

3. A practical sufficient condition. The next theorem provides an easily verifiable sufficient condition for (2.1) and (2.4) to hold.

THEOREM 2. Given an additive complex valued arithmetic function $f$, a sufficient condition for (2.1) and (2.4) to hold is

$$
\sum_{q \beta \leqq n} D^{2}\left(q^{\beta}\right) q^{-\beta}=O\left(D^{2}(n)\right)
$$

or

$$
\sum_{p^{\alpha} \leqq n}\left|f\left(p^{\alpha}\right)\right| p^{-\alpha}=O(D(n))
$$

Proof. It is known [2, p. 31] that there exists an absolute con- 
stant $c_{0}$ such that for any complex valued additive function $g$

$$
\sum_{m \leqq n}|g(m)-A(n)|^{2} \leqq c_{0} D^{2}(n) .
$$

Hence if (3.1) holds then

$$
\begin{aligned}
& \sum_{m \leqq n} \operatorname{Max}_{q^{\beta} \| m}\left|f_{q^{\beta}}(m)-A\left(q^{\beta}\right)\right|^{2} \\
& \leqq \sum_{q^{\beta} \leq n} \sum_{m \leqq n q^{-\beta}}\left(2\left|f_{q^{\beta}}(m)-A\left(q^{\beta}\right)\right|^{2}+2\left|f\left(q^{\beta}\right)\right|^{2}\right) \\
& \leqq 2 c_{0} n \sum_{q^{\beta} \leq n} D^{2}\left(q^{\beta}\right) q^{-\beta}+2 n D^{2}(n) \\
&=O\left(n D^{2}(n)\right)
\end{aligned}
$$

which guarantees that (2.2) holds. Noting that for $m \leqq n, q^{\beta} \| m$ and $q^{\beta}<L(m)$, we must have $q^{\beta} \leqq n^{1 / 2}$, it follows from Schwarz's inequality and the lemma that

$$
\begin{aligned}
& \sum_{m \leqq n} \operatorname{Max}_{\substack{q^{\beta} \mid m \\
S(m)<q^{\beta}<L(m)}} \operatorname{Max}_{\boldsymbol{r}\left(m, q^{\beta}\right) \leq k<q^{\beta}}\left|A(k)-A\left(\boldsymbol{r}^{\gamma}\right)\right|^{2} \\
& \leqq \sum_{m \geqq n} \sum_{\substack{q^{\beta} \mid m \\
\mathscr{S}(m)<q^{\beta}<L(m)}} D^{2}\left(q^{\beta}\right) \sum_{r^{\gamma}\left(m, q^{\beta}<<p^{\alpha}<q^{\beta}\right.} p^{-\alpha} \\
& \leqq \sum_{q^{\beta} \leqq n^{1 / 2}} D^{2}\left(q^{\beta}\right) \sum_{p^{\alpha}<q^{\beta}} p^{-\alpha} \sum_{m \in \mathscr{S}\left(n q-\beta, q^{\beta}, p^{\alpha}\right)} 1 \\
& \leqq c_{1} n \sum_{q^{\beta} \leqq n} D^{2}\left(q^{\beta}\right)\left(q^{\beta} \log q^{\beta}\right)^{-1} \sum_{p^{\alpha}<q^{\beta}} p^{-\alpha} \log p^{\alpha} \\
& =O\left(n \sum_{q \beta \leqq n} D^{2}\left(q^{\beta}\right) q^{-\beta}\right) \\
& =O\left(n D^{2}(n)\right)
\end{aligned}
$$

which guarantees that (2.3) holds. Hence (2.1) and (2.4) hold according to Theorem 1.

Now suppose that (3.2) is true and define the additive function $g$ by $g\left(p^{\alpha}\right)=\left|f\left(p^{\alpha}\right)\right|$. To avoid confusion let $\hat{A}(n)=\sum g\left(p^{\alpha}\right) p^{-\alpha}$ where the sum is over those $p^{\alpha} \leqq n ; A(n)$ is thus reserved for $f$. Note that $D^{2}(n)$ is the same for both $f$ and $g$. We see that

$$
\begin{aligned}
\sum_{m \leqq n} \operatorname{Max}_{k \leqq n}\left|f_{k}(m)-A(k)\right|^{2} \\
\quad \leqq 2 \sum_{m \leqq n}\left(\hat{A}^{2}(n)+g^{2}(m)\right) \\
=2 \sum_{m \leqq n}(g(m)-\hat{A}(n))^{2}+4 \hat{A}(n) \sum_{m \leqq n} g(m) \\
\leqq 2 c_{0} n D^{2}(n)+4 \hat{A}(n) \sum_{q^{\beta} \leqq n} g\left(q^{\beta}\right) \sum_{\substack{m \leq n \\
q^{\beta}|| m\\
}} 1 \\
\leqq 2 c_{0} n D^{2}(n)+4 n\left[\sum_{p^{\alpha} \leqq n}\left|f\left(p^{\alpha}\right)\right| p^{-\alpha}\right]^{2} \\
=O\left(n D^{2}(n)\right) .
\end{aligned}
$$

This completes the proof. 
Examples of functions which satisfy (3.1) and (3.2) are the additive functions determined by $f\left(p^{\alpha}\right)=\log p^{\alpha}$ and $f\left(p^{\alpha}\right)=p^{\alpha}$. An example of a function that satisfies neither (3.1) nor (3.2) is the one determined by $f\left(p^{\alpha}\right)=1$. Any nontrivial function $f$ such as $f\left(p^{\alpha}\right)=$ $\log ^{-1} p^{\alpha}$ for which $\sum\left|f\left(p^{\alpha}\right)\right| p^{-\alpha}$ and $D^{2}(n)$ are bounded satisfies (3.2) but not (3.1).

\section{REFERENCES}

1. H. Halberstam and H.-E. Richert, Sieve Methods, Academic Press, London, 1975.

2. J. Kubilius, Probabilistic Methods in the Theory of Numbers, Translations of Mathematical Monographs, Amer. Math. Soc. Vol. 11, Providence, R. I., 1964.

3. J. B. Rosser and L. Schoenfeld, Approximate formulas for some functions of prime numbers, Illinois J. Math., 6 (1962), 64-94.

Received July 22, 1980 and in revised form October 24, 1980.

Baruch College

City UNIVERSITY OF New YoRK

NEW YoRK, NY 10010 



\section{PACIFIC JOURNAL OF MATHEMATICS}

EDITORS

DONALD BABBITT (Managing Editor)

University of California

Los Angeles, CA 90024

Hugo RossI

University of Utah

Salt Lake City, UT 84112

C. C. MOORE and ANDREW OGG

University of California

Berkeley, CA 94720

\section{J. DugundjI}

Department of Mathematics

University of Southern California

Los Angeles, CA 90007

R. FINN and J. MILGRAM

Stanford University

Stanford, CA 94305

\section{ASSOCIATE EDITORS}
R. ARENS
E. F. BECKENBACH
B. H. NEUManN
F. WOLF
K. YoSHIDA

\section{SUPPORTING INSTITUTIONS}

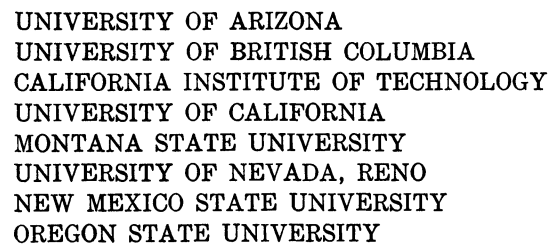

UNIVERSITY OF ARIZONA

UNIVERSITY OF BRITISH COLUMBIA

CALIFORNIA INSTITUTE OF TECHNOLOGY

UNIVERSITY OF CALIFORNIA

MONTANA STATE UNIVERSITY

UNIVERSITY OF NEVADA, RENO

NEW MEXICO STATE UNIVERSITY

OREGON STATE UNIVERSITY

\author{
UNIVERSITY OF OREGON \\ UNIVERSITY OF SOUTHERN CALIFORNIA \\ STANFORD UNIVERSITY \\ UNIVERSITY OF HAWAII \\ UNIVERSITY OF TOKYO \\ UNIVERSITY OF UTAH \\ WASHINGTON STATE UNIVERSITY \\ UNIVERSITY OF WASHINGTON
}

The Supporting Institutions listed above contribute to the cost of publication of this Journal, but they are not owners or publishers and have no responsibility for its content or policies.

Mathematical papers intended for publication in the Pacific Journal of Mathematics should be in typed form or offset-reproduced, (not dittoed), double spaced with large margins. Please do not use built up fractions in the text of the manuscript. However, you may use them in the displayed equations. Underline Greek letters in red, German in green, and script in blue. The first paragraph or two must be capable of being used separately as a synopsis of the entire paper. Please propose a heading for the odd numbered pages of less than 35 characters. Manuscripts, in triplicate, may be sent to any one of the editors. Please classify according to the scheme of Math. Reviews, Index to Vol. 39. Supply name and address of author to whom proofs should be sent. All other communications should be addressed to the managing editor, or Elaine Barth, University of California, Los Angeles, California, 90024.

50 reprints to each author are provided free for each article, only if page charges have been substantially paid. Additional copies may be obtained at cost in multiples of 50 .

The Pacific Journal of Mathematics is issued monthly as of January 1966. Regular subscription rate: $\$ 102.00$ a year (6 Vols., 12 issues). Special rate: $\$ 51.00$ a year to individual members of supporting institutions.

Subscriptions, orders for numbers issued in the last three calendar years, and changes of address shoud be sent to Pacific Journal of Mathematics, P.O. Box 969, Carmel Valley, CA 93924, U.S.A. Old back numbers obtainable from Kraus Periodicals Co., Route 100, Millwood, NY 10546.

\section{PUBLISHED BY PACIFIC JOURNAL OF MATHEMATICS, A NON-PROFIT CORPORATION}

Printed at Kokusai Bunken Insatsusha (International Academic Printing Co., Ltd.). 8-8, 3-chome, Takadanobaba, Shinjuku-ku, Tokyo 160, Japan. 


\section{Pacific Journal of Mathematics}

\section{Vol. 97, No. $2 \quad$ February, 1981}

Patrick Robert Ahern and N. V. Rao, A note on real orthogonal measures . . . . . 249

Kouhei Asano and Katsuyuki Yoshikawa, On polynomial invariants of fibered

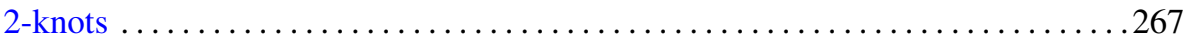

Charles A. Asmuth and Joe Repka, Tensor products for $S L_{2}(\mathscr{K})$. I.

Complementary series and the special representation

Gary Francis Birkenmeier, Baer rings and quasicontinuous rings have a

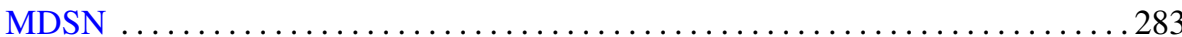

Hans-Heinrich Brungs and Günter Törner, Right chain rings and the generalized

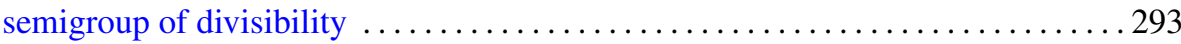

Jia-Arng Chao and Svante Janson, A note on $H^{1} q$-martingales . . . . . . . . . 307

Joseph Eugene Collison, An analogue of Kolmogorov's inequality for a class of

additive arithmetic functions

Frank Rimi DeMeyer, An action of the automorphism group of a commutative ring on its Brauer group

H. P. Dikshit and Anil Kumar, Determination of bounds similar to the Lebesgue

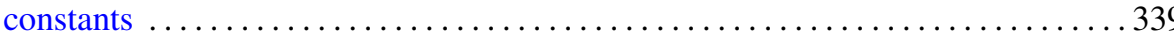

Eric Karel van Douwen, The number of subcontinua of the remainder of the plane

D. W. Dubois, Second note on Artin's solution of Hilbert's 17th problem. Order spaces

Daniel Evans Flath, A comparison of the automorphic representations of GL(3) and its twisted forms

Frederick Michael Goodman, Translation invariant closed $*$ derivations

Richard Grassl, Polynomials in denumerable indeterminates

K. F. Lai, Orders of finite algebraic groups

George Kempf, Torsion divisors on algebraic curves

Arun Kumar and D. P. Sahu, Absolute convergence fields of some triangular matrix methods

Elias Saab, On measurable projections in Banach spaces

Chao-Liang Shen, Automorphisms of dimension groups and the construction of AF algebras

Barry Simon, Pointwise domination of matrices and comparison of $\Phi_{p}$ norms

Chi-Lin Yen, A minimax inequality and its applications to variational inequalities

Stephen D. Cohen, Corrections to: "The Galois group of a polynomial with two indeterminate coefficients"

Phillip Schultz, Correction to: "The typeset and cotypeset of a rank 2 abelian group"

Pavel G. Todorov, Correction to: "New explicit formulas for the $n$th derivative of composite functions"

Douglas S. Bridges, Correction to: "On the isolation of zeroes of an analytic function" 